\title{
The relationship between metabolic syndrome and the incidence of colorectal cancer
}

\author{
JungHyun Lee ${ }^{1}$, Kun Sei Lee ${ }^{1 *}$ (D) Hyeongsu Kim¹, Hyoseon Jeong ${ }^{1}$, Min-Jung Choi ${ }^{1}$, Hai-Won Yoo', \\ Tae-Hwa $\mathrm{Han}^{2}$ and Hyunjung Lee ${ }^{3}$
}

\begin{abstract}
Objectives: This study evaluated the incidence of colorectal cancer (CRC) according to the number of metabolic syndrome (MetS) components.

Methods: Using health checkup and insurance claims data of 6,365,409 subjects, the occurrence of CRC according to stage of MetS by sex was determined from the date of the health checkup in 2009 until December 31, 2018.

Results: Cumulative incidence rates (CIR) of CRC in men and women was 3.9 and 2.8 per $1000(p<0.001)$, respectively. CIR of CRC for the normal, pre-MetS, and MetS groups in men was 2.6, 3.9, and 5.5 per $1000(p<0.001)$ and CIR in women was 2.1, 2.9, and 4.5 per $1000(p<0.001)$, respectively. Compared with the normal group, the hazard ratio (HR) of CRC for the pre-MetS group was 1.25 (95\% Cl 1.17-1.33) in men and 1.09 (95\% Cl 1.02-1.17) in women, and the HR of CRC for the MetS group was 1.54 (95\% Cl 1.43-1.65) in men and 1.39 (95\% Cl 1.26-1.53) in women after adjustment.
\end{abstract}

Conclusions: We found that MetS is a risk factor for CRC in this study. Therefore, the prevention and active management of MetS would contribute to the prevention of CRC.

Keywords: Metabolic syndrome, Colorectal cancer, Relevance, Koreans

\section{Introduction}

Colorectal cancer (CRC) is the third most common cancer worldwide and accounts for $10.2 \%$ of all cancers (approximately 1.8 million people a year) [1]. CRC is the second most common cancer after stomach cancer in Korea [1], so identifying and managing risk factors is the first step in preventing CRC. In Korea, the incidence of CRC has increased over the past decade, and the ageadjusted incidence per 100,000 men and women has increased from 26.2, 16.4 in 1999 to 40.4, 22.4 in 2016, respectively [2]. Major risk factors for CRC include genetic predisposition, Western dietary habits, lifestyle (smoking, drinking, physical activity, etc.), and metabolic diseases (obesity, insulin resistance, etc.) [3].

\footnotetext{
* Correspondence: kunsei.lee@kku.ac.kr

${ }^{1}$ Department of Preventive Medicine, School of Medicine, Konkuk University, Neungdongro 120, Gwangjin-gu, Seoul 05029, Korea

Full list of author information is available at the end of the article
}

Metabolic syndrome (MetS) is a cluster of metabolic risk factors that includes abdominal obesity, hypertension, hyperglycemia, and dyslipidemia; several definitions have been suggested using different criteria [4, 5]. More than $20 \%$ of adults are known to have MetS [6], but its prevalence worldwide varies depending on race, environmental factors, the age and gender composition of the population, genetic differences, physical activity level, eating habits, and differences in measurement standards [7, 8]. The estimated total prevalence of MetS for adults in Korea is 26.9\%: $30.0 \%$ in males and $24.6 \%$ in females [9].

Some studies on the correlation between metabolic syndrome and CRC have been reported recently, but many studies have been conducted in Western countries and races [10-13]. However, studies on Asian races are still limited to East Asian countries such as Taiwan and Japan $[14,15]$. In addition, the study population is limited to those who are screened at only university hospital

(c) The Author(s). 2020 Open Access This article is distributed under the terms of the Creative Commons Attribution 4.0 International License (http://creativecommons.org/licenses/by/4.0/), which permits unrestricted use, distribution, and reproduction in any medium, provided you give appropriate credit to the original author(s) and the source, provide a link to the Creative Commons license, and indicate if changes were made. The Creative Commons Public Domain Dedication waiver (http://creativecommons.org/publicdomain/zero/1.0/) applies to the data made available in this article, unless otherwise stated. 
screening centers, so it is not easy to generalize to the entire population [14]. Also there is a limitation that it is difficult to produce a meaningful result because of the short observation period and the lack of cancer cases [15].

In order to complement the limitations of previous research conducted on Asian races, this study evaluated the incidence of CRC according to the number of MetS components using the health checkup data and insurance claims data from the National Health Insurance Service (NHIS) in Korea.

\section{Methods}

\section{Study design and population}

This was a retrospective observational study that used health checkup and insurance claims data from the NHIS (Fig. 1). NHIS is constructing and providing health database that includes medical history, treatment, type of disease, and prescription history of all Koreans who use health checkup or medical service under national health insurance. The database has been operating continuously, and about 50 million people's medical data are monitored from 2002 to 2018. In detail, the National Health Information database is divided into Qualification database, Treatment database, and Health check-up database. The National
Health Information database is significant in terms of representation because it monitors medical history of all Koreans, and it is also useful because it can be linked and analyzed with other administrative data through the social security number. The Health check-up database used in this study is very suitable for the purpose of research because it contains the actual measurement value such as blood pressure, blood sugar, triglycerides, HDL, and health habits for those who undergo health checkups every 2 years.

The source population was defined as those who had had health checkups in 2009. While this comprised $15,036,607$ people, only $9,927,538$ people were actually examined. Of these, 3,562,129 were excluded for the following reasons:

1. Age $<30$ years old or $\geq 70$ years old.

2. Missing MetS checkup items (fasting blood sugar, systolic and diastolic blood pressure, triglycerides (TG), high-density lipoprotein cholesterol (HDL-C), abdominal obesity); height $<120$ or $>200 \mathrm{~cm}$, weight $<20$ or $>200 \mathrm{~kg}$.

3. If the subject has a history of cardiovascular disease, cerebrovascular disease, or cancer; cardiovascular diseases (ischemic heart disease I20-I25, cardiac failure I42 or I50), atrial fibrillation (I48),

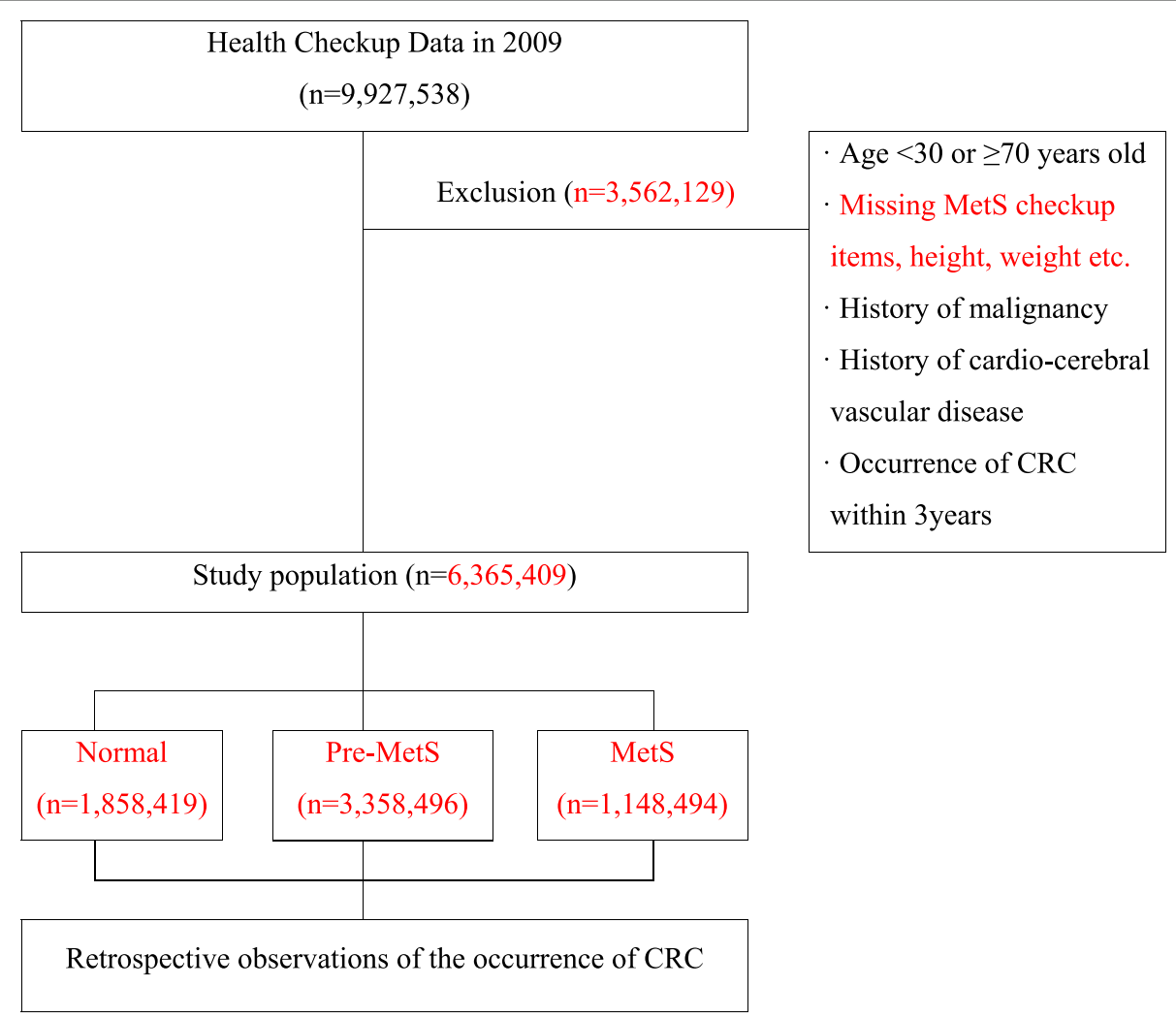

Fig. 1 Study design and selection of the study population 
cerebrovascular disease (I60-I69), circulatory system disease (I00-199), and beneficiaries for cancer (C00-C97).

4. Colorectal cancer found within 3 years after health checkups in 2009.

Consequently, the final study population came to $6,365,409$; they were divided into three groups depending on the number of MetS components. There were $1,858,419,3,358,496$, and $1,148,494$ in the normal, pre-MetS, and MetS groups, respectively. Using insurance claims data, the occurrence of CRC was checked in the study population from the date of the health checkups in 2009 to December 31, 2018. Mean follow-up period is 9.3 years.

\section{Measurements}

\section{Dependent variable}

The dependent variable was the occurrence of CRC, as identified operationally from insurance benefit claims data, with codes $\mathrm{C} 18-\mathrm{C} 20$ as a primary diagnosis from the International Classification of Diseases-Tenth revision and V193 as a special code. A special code is a system whereby the economic burden on patients diagnosed with cancer, severe burns, cerebrovascular and heart diseases, or intractable diseases is reduced by decreasing the copayment. If a disease is claimed with this special code, it means that the diagnosis is more accurate than a claim disease without a special code.

\section{Independent variable}

The independent variable was the stage of MetS, which was classified into three groups according to the criteria of modified National Cholesterol Education ProgramAdult Treatment Panel III (NECP-ATP III, which are the most agreed-upon criteria [16]. MetS refers to subjects with at least three of the following five factors: (1) abdominal obesity (waist circumference $\geq 90 \mathrm{~cm}$ for men, $\geq 85 \mathrm{~cm}$ for women); (2) elevated blood pressure (systolic BP $\geq 130 \mathrm{mmHg}$ or diastolic $\mathrm{BP} \geq 85 \mathrm{mmHg}$ or treatment of previously diagnosed hypertension); (3) elevated fasting glucose $(\geq 100 \mathrm{mg} / \mathrm{dL}$ or treatment of previously diagnosed diabetes mellitus); (4) high TG ( $\geq$ $150 \mathrm{mg} / \mathrm{dL}$ or drug treatment for high TG); and (5) low HDL-C (<40 mg/dL for men, <50 mg/dL for women or drug treatment for low HDL-C). The subjects were placed in the pre-MetS group with one or two MetS factors and the Normal group with no MetS factors.

\section{Adjusted variables}

The study population was divided into two subsets by gender. Next, age, health behaviors, family history, and laboratory data from the health checkup were used as adjustment variables. Age was divided into 10-year intervals, and health behaviors were selected from smoking, drinking, and physical activities in the questionnaire. Smoking was categorized into three groups: never smoked, smoked in the past but no longer, and currently smoking. Alcohol consumption was categorized into four groups based on the drinking frequency: nondrinker, 2-3 times per month, 1-4 times per week, and almost every day. Physical activity group was categorized into three groups based on frequency: never, 1-4 times per week, and almost every day. Family history of cancer was divided into two groups of yes or no. Height, weight, body mass index (BMI), hemoglobin, serum creatinine, total cholesterol, and alanine aminotransferase (ALT), which were health checkup items, were used as laboratory findings, and as continuous variables. BMI $\left(\mathrm{kg} / \mathrm{m}^{2}\right)$, hemoglobin $(\mathrm{g} / \mathrm{dL})$, and serum creatinine $(\mathrm{mg} / \mathrm{dL})$ are categorized according to the criteria of Korean health screening [17]. Total cholesterol (mg/dL) and ALT (IU/ L) were used in the model as continuous variables, and the original data values were increased by ten times to improve the readability of the hazard ratio.

Height $(\mathrm{cm})$ was divided into four groups according to the quartiles of height distribution for each sex $(<167$, $167-171,172-174, \geq 175 \mathrm{~cm}$ for men; < 154, 154-156, $157-160, \geq 161 \mathrm{~cm}$ for women). Weight (kg) also was divided into four groups according to the quartiles of weight distribution for each sex $(<64,64-69,70-76$, $\geq 77 \mathrm{~cm}$ for men; <52, 52-55, 56-61, $\geq 62 \mathrm{~kg}$ for women). BMI was categorized into five groups: underweight $(<18.5)$, normal (18.5-22.9), overweight (23.0$24.9)$, obesity (25-29.9), and altitude obesity $(\geq 30)$. Hemoglobin was categorized into three groups and differed by sex: normal (men: >12.0, women: > 10.0), mild or moderate anemia (men: 10.0-12.0, women: 8.0-10.0), severe anemia (men: < 10.0, women: <8); serum creatinine was categorized into two groups: normal $(<1.5)$, abnormal $(\geq 1.5)$. Total cholesterol and ALT were also divided into four groups for according to the quartiles of their distribution for each sex (total cholesterol $<173$, 173-194, 195-218, $\geq 219$, ALT < 18, 18-24, 25-35, $\geq 36$ for men; total cholesterol $<171,171-192,193-217, \geq 218$, ALT $<13,13-15,16-21, \geq 22$ for women) for descriptive analysis.

\section{Statistical analysis}

We summarized the frequency of study population for related variables according to the number of MetS components, and calculated the cumulative incidence rate (CIR) and incidence density (ID) of CRC. CIR is the incidence per 1000 person and ID is the incidence per 10, 000 person-years (PY). PY was calculated as the time from the baseline examination to the date of CRC diagnosis, the date of death, or December 31, 2018 when who survives without diagnosis of CRC. 
Next, we compared the frequency between variables using the chi-square test. To analyze the risk of developing CRC due to MetS, Cox proportional hazard regression was applied. All variables affecting the incidence of CRC were considered stepwise and five Cox proportional hazard models were fitted, including one unadjusted model for comparison.

Model 1 was adjusted for age. Model 2 was adjusted for health behavior (smoking, exercise). Model 3 was adjusted for family history cancer. Model 4 was adjusted for the laboratory findings (height, weight, hemoglobin, and other relevant values). Model 5 was adjusted for the laboratory findings (body mass index, creatinine, hemoglobin, and other relevant values). The results are summarized as the hazard ratio (HR) and 95\% confidence interval $(95 \% \mathrm{CI})$.

A level of $\alpha=0.05$ was used to determine the significance of the models and variables. All statistical analyses were performed using SAS ver. 9.1 (SAS Institute, Cary, NC, USA).

\section{Ethics considerations}

The study was approved by the institutional review board of Konkuk University (7001355-201909-E-100).

\section{Results}

\section{CIR and ID of CRC according to the number of Mets components in men}

The number of study population and the CIR of CRC in men were 3,695,923 and 3.9 (Table 1). The CIR of CRC by MetS stage was 2.6, 3.9, and 5.5 for the normal, preMetS, and MetS groups, respectively $(p<0.001)$.

The ID of CRC in men was 4.2 (Table 1). The ID of CRC by MetS stage was 2.8, 4.2, and 6.0 for the normal, pre-MetS, and MetS groups, respectively $(p<0.001)$.

The number of study population and the CIR and the ID of CRC for the other variables in men were summarized in Table 1.

\section{CIR and ID of CRC according to the number of Mets components in women}

The number of study population and the CIR of CRC in women were 2,669,486 and 2.8 (Table 2). The CIR of CRC by MetS stage was 2.1, 2.9, and 4.5 for the normal, pre-MetS, and MetS groups, respectively $(p<0.001)$.

The ID of CRC in women was 3.0 (Table 2). The ID of CRC by MetS stage was 2.2, 3.1, and 4.8 for the normal, pre-MetS, and MetS groups, respectively $(p<0.001)$.

The number of study population and the CIR and the ID of CRC for the other variables in women were summarized in Table 2.
Risk of the number of Mets components on CRC in men and women

In men, the $\mathrm{HR}$ of $\mathrm{CRC}$ for the pre-MetS group compared with the normal group before adjustment (unadjusted model) was 1.50 (95\% CI 1.43-1.57), and the HR for the MetS group was 2.16 (95\% CI 2.06-2.28) (Table 3). After full adjustment (model 5), the HR for the pre-MetS group and MetS group was 1.25 (95\% CI 1.17-1.33) and 1.54 (95\% CI 1.43-1.65).

In women, the HR of CRC for the pre-MetS group compared with the normal group before adjustment (unadjusted model) was 1.39 (95\% CI 1.32-1.46), and the HR for the MetS group was 2.15 (95\% CI 2.01-2.30) (Table 4). After full adjustment (model 5), the HR for the pre-MetS group and MetS group was 1.09 (95\% CI $1.02-1.17$ ) and 1.39 (95\% CI 1.26-1.53).

\section{Discussion}

To investigate the effect of MetS on the incidence of CRC, we analyzed about 6 million medical claim and check-up data that had the high external validity with large sample size and average follow-up period of 9.3 years per person from NHIS in Korea.

The results of the study revealed there is a positive association between MetS and the incidence of CRC. This supports previous findings that MetS is the main factor expediting tumor growth [18-20].

After analyzing 18 studies $(687,413$ people) of MetS and CRC, Jinjuvadia et al. [18] reported that MetS increases the occurrence of CRC [relative rate (RR), 1.30; 95\% CI 1.18-1.43] and colorectal adenoma (RR, 1.37; 95\% CI 1.26-1.494). The Atherosclerosis Risk in Communities (ARIC) follow-up observational study of 14,000 Americans identified MetS as the main factor (RR, 1.49; 95\% CI 1.0-2.4) responsible for the occurrence of CRC [19]. With 12 years of follow-up, the Metabolic Syndrome and Cancer Project determined that the risk of CRC in men and women increased by 1.25 (95\% CI 1.18-1.32) and 1.14 (95\% CI 1.06-1.22), respectively [20]. Numerous other studies also identify MetS as increasing the risk of CRC [21, 22].

Although the mechanism of MetS in the development of CRC is not clear, it is thought to be related to hyperinsulinism and insulin resistance [23, 24], which increases insulin-like growth factor-1 levels. In addition, adipocyte-secreted hormones such as adiponectin, leptin, and resistin [25]; the greater proportion of Firmicutes and lower proportion of Bacteroidetes within the large intestine [26, 27]; and a high-fat, low-fiber diet [28] are all related to the occurrence of CRC. Since it is important to understand the pathological mechanism of CRC related to MetS [29], additional studies need to examine how to prevent CRC as MetS progresses [30]. 


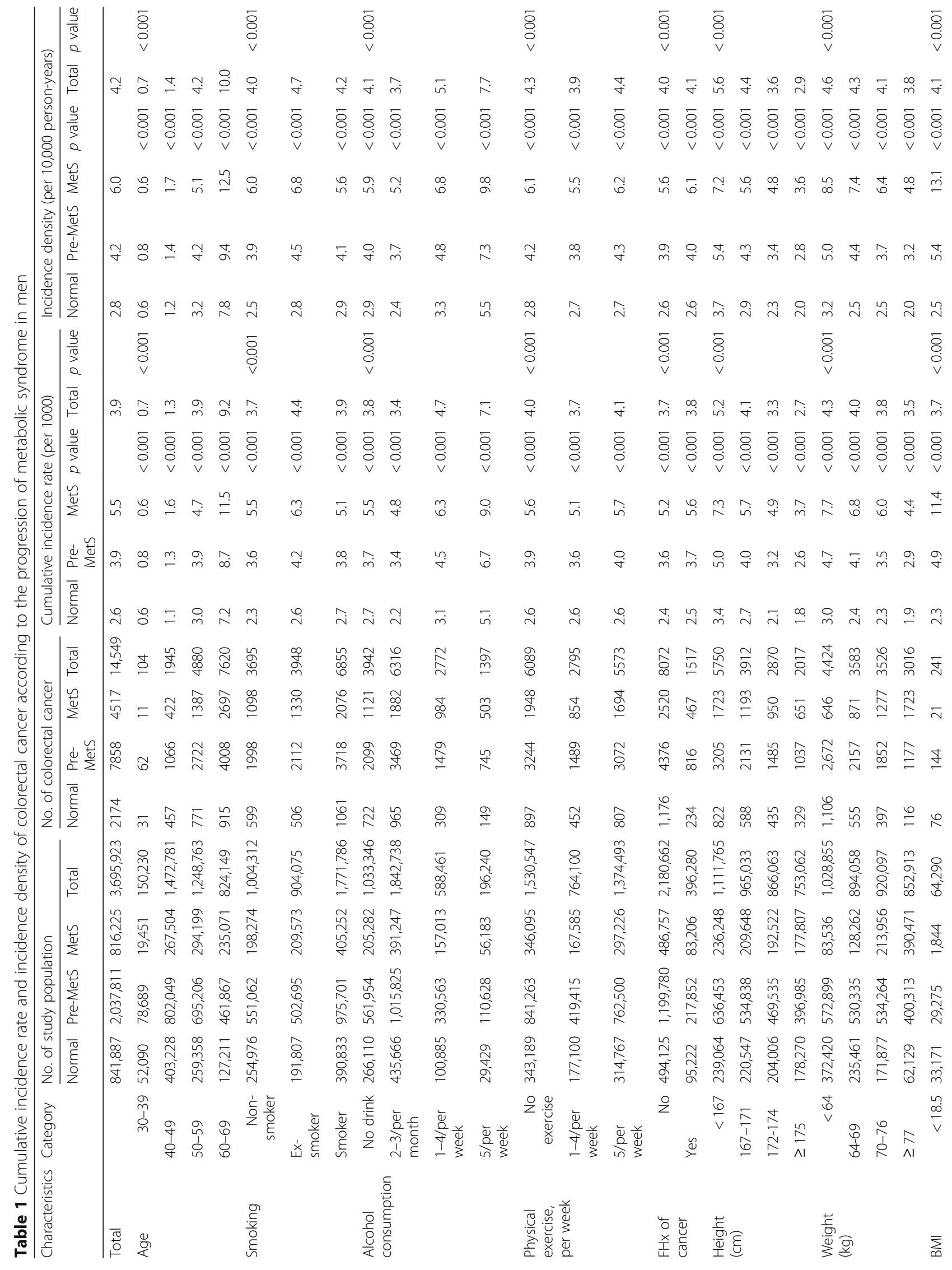




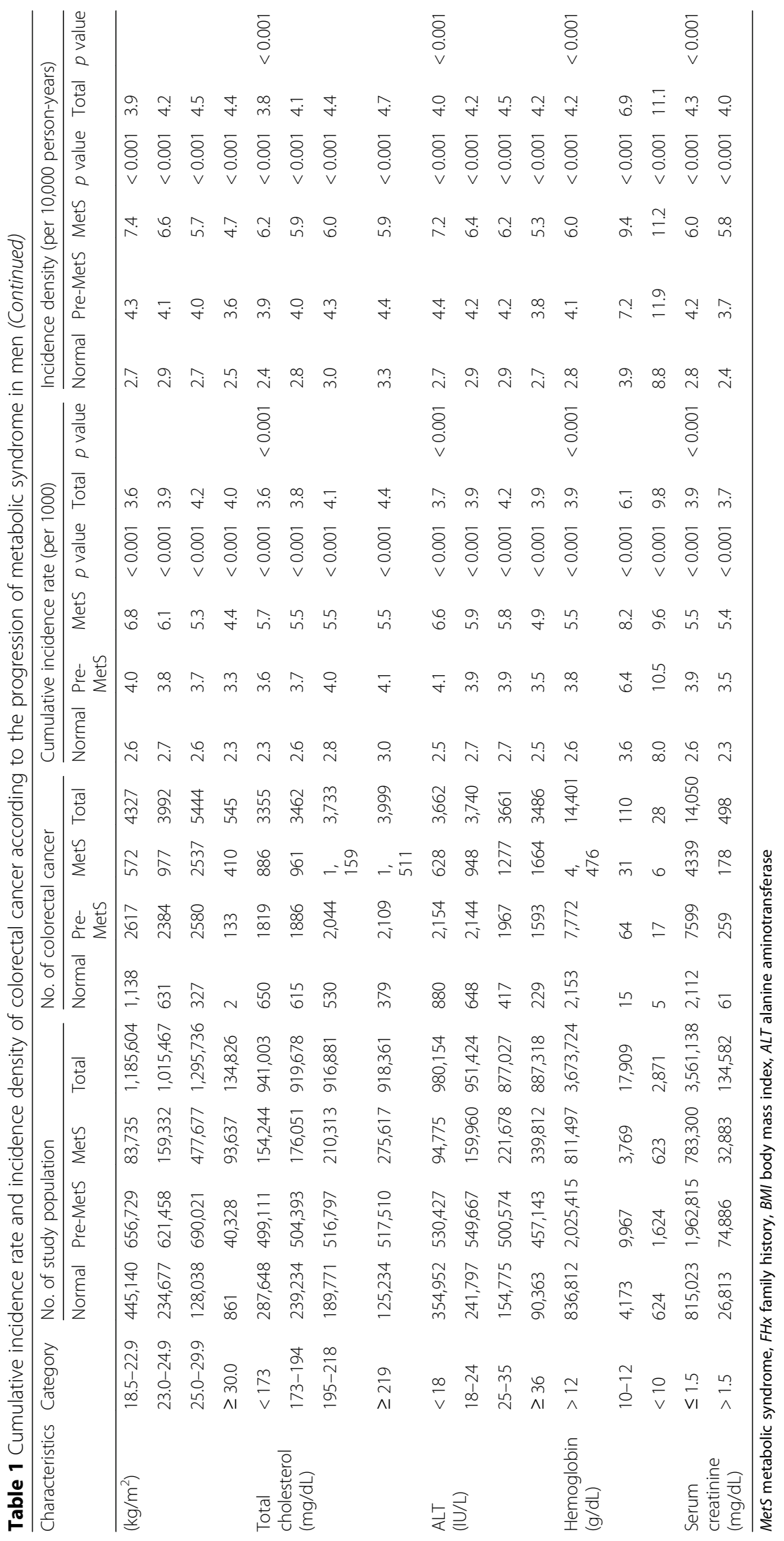




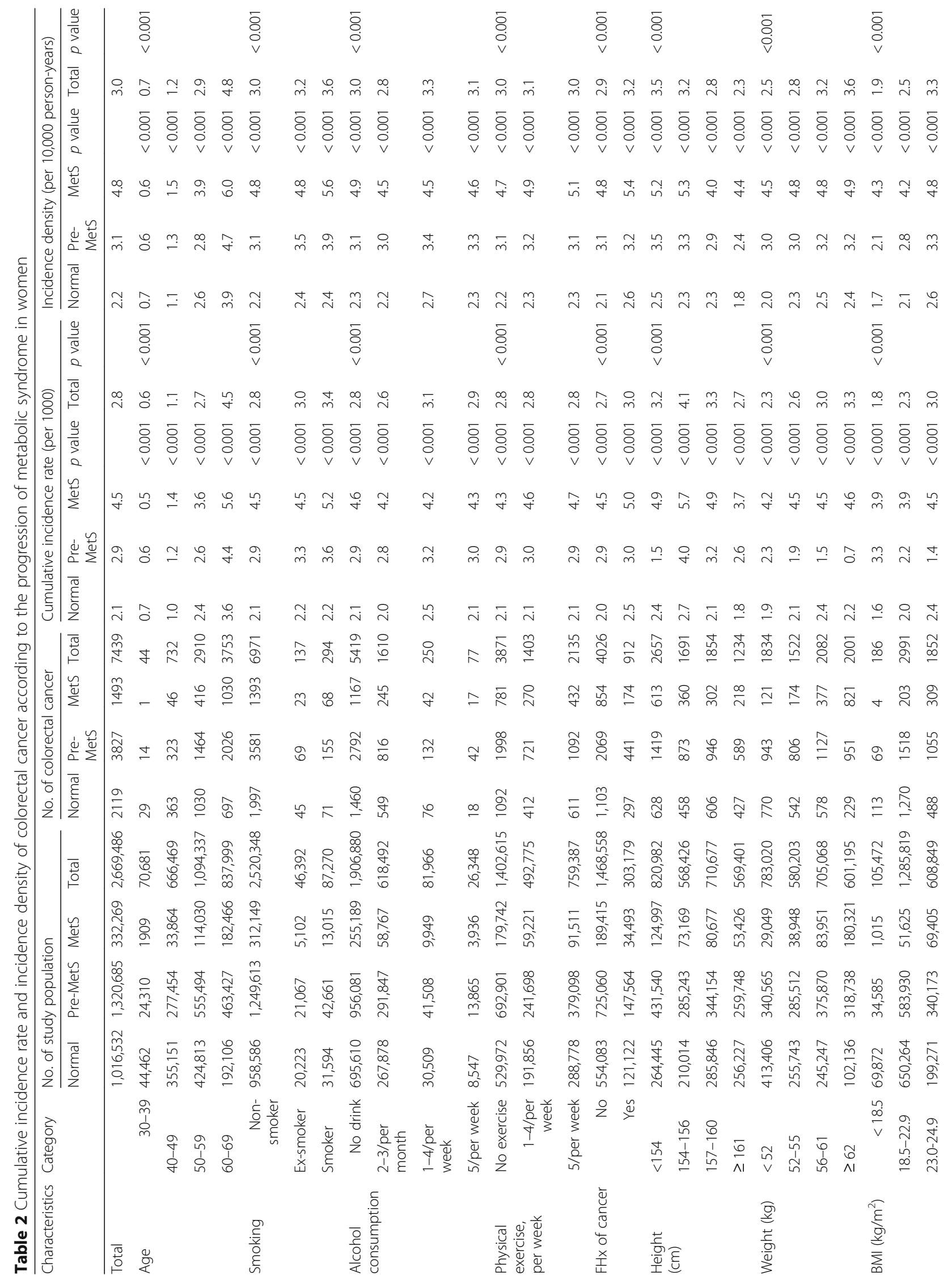




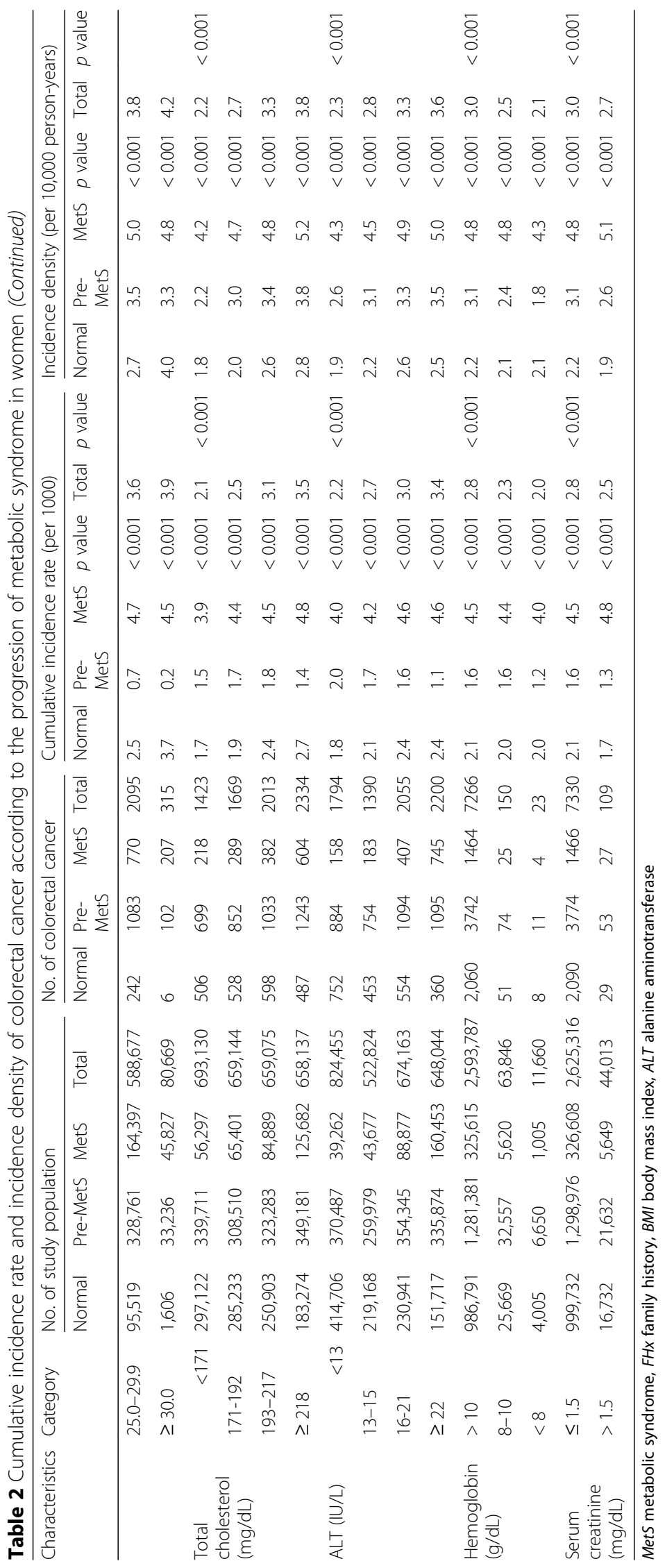




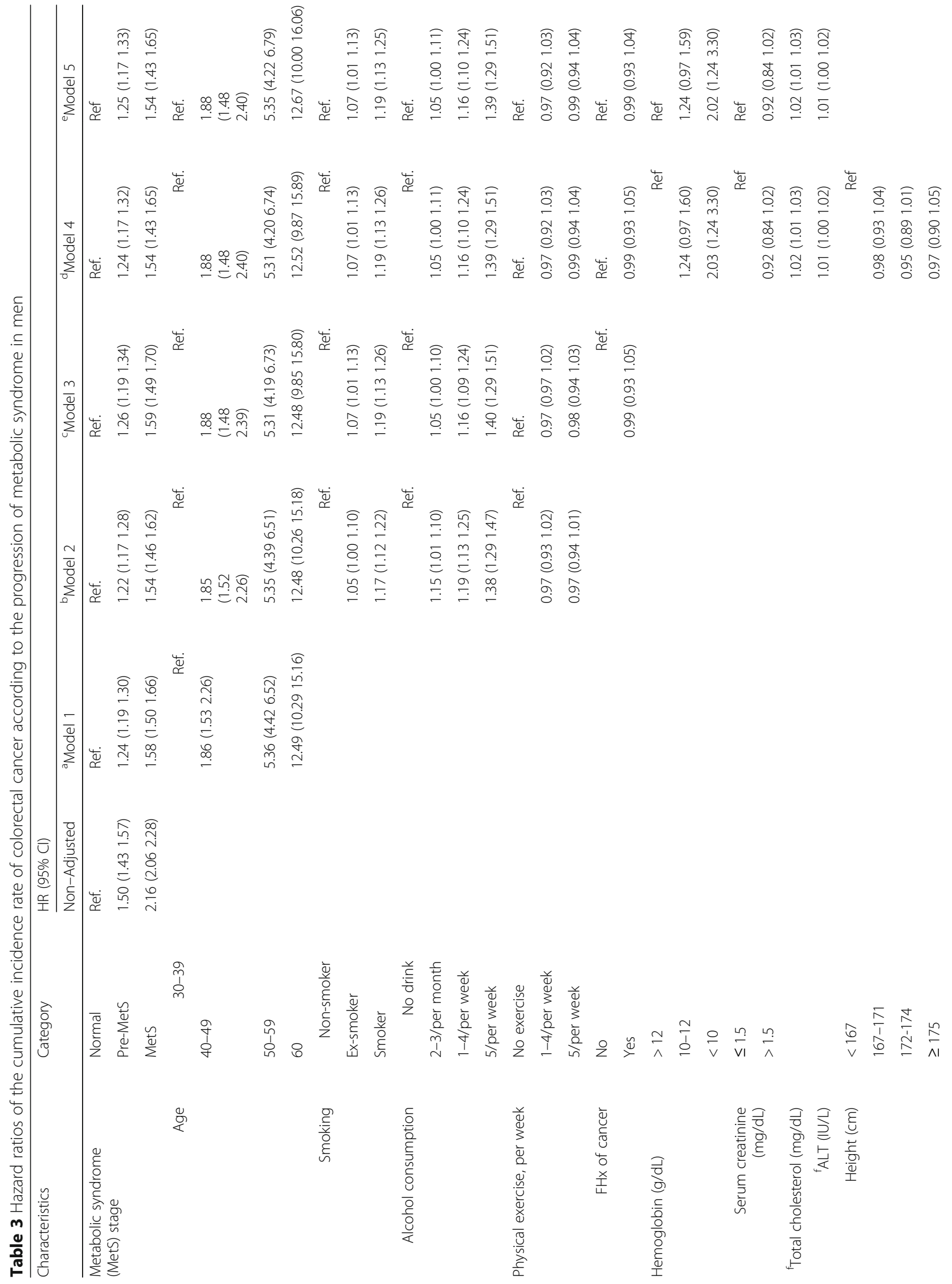




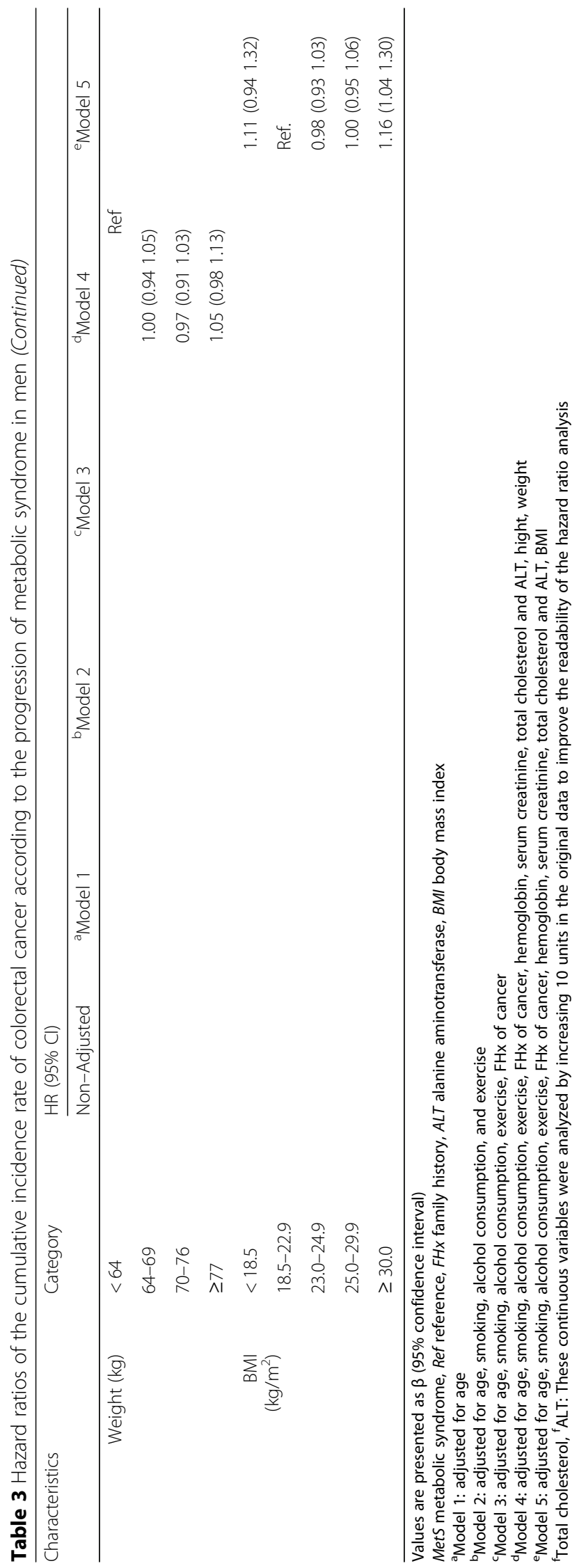


Table 4 Hazard ratios of the cumulative incidence rate of colorectal cancer according to the progression of metabolic syndrome in women

\begin{tabular}{|c|c|c|c|c|c|c|c|}
\hline \multirow[t]{2}{*}{ Characteristics } & \multirow[t]{2}{*}{ Category } & \multicolumn{6}{|l|}{ HR (95\% Cl) } \\
\hline & & Non-Adjusted & ${ }^{\mathrm{a}}$ Model 1 & ${ }^{\mathrm{b}}$ Model 2 & ${ }^{c}$ Model 3 & ${ }^{\mathrm{d}}$ Model 4 & ${ }^{\mathrm{e}}$ Model 5 \\
\hline \multirow{3}{*}{$\begin{array}{l}\text { Metabolic syndrome } \\
\text { (MetS) stage }\end{array}$} & Normal & Ref. & Ref. & Ref. & Ref. & Ref & Ref. \\
\hline & Pre-MetS & 1.39 (1.32 1.46) & $1.14(1.081 .20)$ & 1.13 (1.07 1.19) & $1.12(1.051 .20)$ & 1.09 (1.01 1.16) & 1.09 (1.02 1.17) \\
\hline & MetS & 2.15 (2.01 2.30) & $1.50(1.401 .61)$ & 1.49 (1.39 1.59) & $1.52(1.401 .66)$ & $1.39(1.261 .52)$ & 1.39 (1.26 1.53) \\
\hline \multirow{7}{*}{ Smoking } & $30-39$ & & Ref. & Ref. & Ref. & Ref. & Ref. \\
\hline & $40-49$ & & 1.74 (1.28 2.36) & 1.77 (1.30 2.41) & 1.66 (1.15 2.40) & 1.62 (1.12 2.34) & $1.64(1.132 .37)$ \\
\hline & $50-59$ & & 4.03 (2.99 5.43) & 4.19 (3.10 5.66) & $3.89(2.715 .59)$ & $3.71(2.585 .33)$ & $3.76(2.625 .40)$ \\
\hline & 60 & & $6.38(4.748 .60)$ & 6.74 (4.99 9.12) & 6.37 (4.44 9.15) & $5.97(4.158 .60)$ & $6.04(4.208 .68)$ \\
\hline & Non-smoker & & & Ref. & Ref. & Ref. & Ref. \\
\hline & Ex-smoker & & & 1.25 (1.06 1.49) & $1.32(1.081 .60)$ & 1.31 (1.07 1.59) & $1.32\left(\begin{array}{ll}1.08 & 1.60)\end{array}\right.$ \\
\hline & Smoker & & & 1.25 (1.10 1.41) & $1.23(1.061 .43)$ & $1.23(1.061 .43)$ & $1.23(1.06$ 1.43) \\
\hline \multirow[t]{4}{*}{ Alcohol consumption } & No drink & & & Ref. & Ref. & Ref. & Ref. \\
\hline & 2-3/per month & & & $1.11(1.05$ 1.18) & $1.12(1.051 .21)$ & $1.12(1.051 .21)$ & $1.12\left(\begin{array}{ll}1.05 & 1.20)\end{array}\right.$ \\
\hline & 1-4/per week & & & $1.20(1.051 .36)$ & 1.13 (0.96 1.33) & $1.13(0.96$ 1.33) & $1.13(0.96$ 1.33) \\
\hline & 5/per week & & & 0.99 (0.79 1.24) & $1.07(0.821 .40)$ & 1.07 (0.82 1.40) & $1.07\left(\begin{array}{l}0.82 \\
1.40)\end{array}\right.$ \\
\hline \multirow[t]{3}{*}{ Physical exercise, per week } & No exercise & & & Ref. & Ref. & Ref. & Ref. \\
\hline & 1-4/per week & & & $1.04(0.981 .10)$ & $1.03(0.961 .11)$ & $1.03(0.961 .11)$ & $1.03(0.961 .12)$ \\
\hline & 5/per week & & & $0.96(0.911 .01)$ & 0.96 (0.89 1.02) & 0.95 (0.89 1.02) & $0.96\left(\begin{array}{lll}0.90 & 1.02\end{array}\right)$ \\
\hline \multirow[t]{2}{*}{ FHx of cancer } & No & & & & Ref. & Ref. & Ref. \\
\hline & Yes & & & & $1.09(1.011 .17)$ & $1.09(1.011 .17)$ & 1.09 (1.01 1.17) \\
\hline \multirow{3}{*}{$\begin{array}{l}\text { Hemoglobin } \\
(\mathrm{g} / \mathrm{dL})\end{array}$} & $>10$ & & & & & Ref & Ref \\
\hline & $8-10$ & & & & & $1.15(0.941 .40)$ & $1.15(0.941 .40)$ \\
\hline & $<8$ & & & & & $0.91(0.551 .51)$ & $0.90(0.541 .50)$ \\
\hline \multirow{2}{*}{$\begin{array}{l}\text { Serum creatinine } \\
(\mathrm{mg} / \mathrm{dL})\end{array}$} & $\leq 1.5$ & & & & & Ref & Ref \\
\hline & $>1.5$ & & & & & $0.92(0.751 .13)$ & $0.92(0.751 .13)$ \\
\hline eTotal cholesterol(mg/dL) & & & & & & $1.03\left(\begin{array}{ll}1.01 & 1.04\end{array}\right)$ & $1.03\left(\begin{array}{lll}1.01 & 1.04)\end{array}\right.$ \\
\hline${ }^{\mathrm{f}} \mathrm{ALT}(\mathrm{IU} / \mathrm{L})$ & & & & & & $1.00(0.991 .02)$ & $1.00(0.991 .02)$ \\
\hline \multirow[t]{4}{*}{ Height (cm) } & $<154$ & & & & & Ref & \\
\hline & $154-156$ & & & & & 1.05 (0.97 1.13) & \\
\hline & $157-160$ & & & & & $0.91(0.881 .03)$ & \\
\hline & $\geq 161$ & & & & & $0.94\left(\begin{array}{lll}0.85 & 1.03)\end{array}\right.$ & \\
\hline \multirow[t]{4}{*}{ Weight (kg) } & $<52$ & & & & & Ref & \\
\hline & $52-55$ & & & & & $1.03(0.941 .12)$ & \\
\hline & $56-61$ & & & & & $1.09\left(\begin{array}{ll}1.01 & 1.19\end{array}\right)$ & \\
\hline & $\geq 62$ & & & & & $1.18(1.081 .29)$ & \\
\hline \multirow[t]{5}{*}{${ }^{\mathrm{e}} \mathrm{BMI}\left(\mathrm{kg} / \mathrm{m}^{2}\right)$} & $<18.5$ & & & & & & $1.01(0.841 .22)$ \\
\hline & $18.5-22.9$ & & & & & & Ref \\
\hline & $23.0-24.9$ & & & & & & $1.09\left(\begin{array}{lll}1.01 & 1.17\end{array}\right)$ \\
\hline & $25.0-29.9$ & & & & & & $1.13(1.05$ 1.22) \\
\hline & $\geq 30.0$ & & & & & & $1.20(1.03$ 1.39) \\
\hline
\end{tabular}

Values are presented as $\beta$ (95\% confidence interval)

MetS metabolic syndrome, Ref reference, FHx family history, ALT alanine aminotransferase, BMI body mass index

${ }^{a}$ Model 1: adjusted for age

${ }^{\mathrm{b}}$ Model 2: adjusted for age, smoking, alcohol consumption, and exercise

'Model 3: adjusted for age, smoking, alcohol consumption, exercise, FHx of cancer

dModel 4: adjusted for age, smoking, alcohol consumption, exercise, FHx of cancer, hemoglobin, serum creatinine, total cholesterol and ALT, hight, weight

'Model 5: adjusted for age, smoking, alcohol consumption, exercise, FHx of cancer, hemoglobin, serum creatinine, total cholesterol and ALT, BMI

${ }^{\mathrm{f}}$ Total cholesterol, ${ }^{\mathrm{f}} \mathrm{ALT}$ : These continuous variables were analyzed by increasing 10 units in the original data to improve the readability of the hazard

ratio analysis 
In this study, pre-MetS group had a 25\% higher risk of CRC and MetS group had a 54\% higher risk of CRC than Normal group in men based on the full adjustment model, and pre-MetS group had a 9\% higher risk of CRC and MetS group had a 39\% higher risk of CRC than Normal group in women. The risk of Mets on incidence of CRC was slightly higher in men than in women, and all were significant.

However, some previous studies showed different risk ratios by gender [10, 12, 31, 32]. The reason for this is difference in the number of study subjects, study design, and fundamental biological differences between males and females. Although this study showed the positive association between MetS and the incidence of CRC, further investigation is needed as to the question of how men and women may be affected by metabolic abnormalities in terms of CRC risk [13].

Lifestyle has been known to be a major factor associated with CRC, and it is known that the risk of cancer gradually decreases if healthy lifestyles are practiced in stages [33]. This study found that drinking alcohol and smoking were related to the risk of CRC. Other studies also shown that smoking [34] and drinking alcohol have carcinogenic effects and promote cancer, especially in the case of drinking alcohol, moderate amounts of drinking alcohol can lead to an increase in CRC [35]. Education programs for lifestyle improvements should be conducted to reduce the incidence of colorectal cancer [36]. It has been suggested as an effective way to raise awareness, knowledge, and screening rate for colorectal cancer screening $[37,38]$.

There are some studies [39-41] that consider height in the analysis as risk factors for colorectal cancer, and the results of the analysis are also reported to be significant. Based on these similar previous studies, this study considered the relationship between height and colorectal cancer but found no significant correlation. There was also no significant association between weight and colorectal cancer.

Previous studies of Asian races have limits, such as a lack of representativeness or only a few variables were examined. Our study identified MetS as a risk factor for CRC after adjusting for various variables and determined the magnitude of the risk using national health checkup and insurance claims data in Korea. Because there are ethnic differences in the relationship between MetS and cancer $[13,25,42]$, the presentation of risk ratios for Asians using large data and long follow-up period sets is a significant research achievement. Study on the relationship between metabolic and disease occurrence for Asian races [43] should be conducted and other approaches to mitigate health risks need to be reviewed [44]. In addition, this study has some newly informative knowledge as follows. First, this study is meaningful in that it attempts to represent the entire Korean population using the National Health Insurance Corporation's claim data. Second, this study is the most recent longterm data taken from the initial establishment of the data source to the latest data. Third, unlike other studies, this study considered the incubation period sufficiently to closely observe the association of colorectal cancer risk due to metabolic syndrome. The incubation period was set to 3 years, and the analysis was performed except for patients with colorectal cancer who developed within 3 years of the observation. Fourth, this study was able to understand the risk of colorectal cancer in more detail by classifying subjects according to the number of factors of metabolic syndrome rather than whether they were metabolic syndrome.

This study has some limitations. First, we did not consider changes in the risk of the number of metabolic components on CRC in men and women in the study population after it was diagnosed, since we used only the health check-up data for 2009. This should be examined in a future study. Second, we did not adjust for some variables, such as the consumption of meat, which is a known risk factor for CRC, because we used secondary data. Lastly, health screening programs are being provided to all Koreans regardless of income, and the participation rate is also increasing from $72.9 \%$ in 2012 to $78.5 \%$ in 2017 [17]. However, it is mandatory for industrial workers to be screened, and the rate of participation of industrial workers is relatively higher than that of self-employees [45]. Therefore, this study cannot exclude the possibility of health workers effect.

\section{Conclusions}

This study investigated the relationship between MetS and CRC using national health check-up and insurance claims data for Korea. It showed that MetS was a risk factor for the occurrence of CRC.

From a clinical and public health perspective, Mets has emerged as an important disease that requires early management and more thorough management and prevention of Mets are needed to prevent CRC based on the results of this study with long-term follow-up and large-scale of Asian subjects.

\section{Abbreviations \\ CIR: Cumulative incidence rates; CRC: Colorectal cancer; ID: Incidence density; MetS: Metabolic syndrome; NCEP-III: National Cholesterol Education Program} Adult Treatment Panel III; NHIS: National Health Insurance Service

Acknowledgments

We thank the NHIS for permission to use the NHIS data (NHIS-2019-1-404).

\section{Authors' contributions}

$\mathrm{JH}$ Lee contributed to interpretation of data and drafting the article. K Lee contributed to conception and design of study and revising the article critically for important intellectual content. $\mathrm{H} \mathrm{Kim}$ and $\mathrm{H}$ Lee contributed to data analysis and discussion of the results. $\mathrm{H}$ Jeong and MJ Choi contributed 
to interpretation of results. HW Yoo and TH Han contributed to data extraction, revising the article critically for important intellectual content, and final approval of the version to be published. The authors read and approved the final manuscript.

\section{Funding}

This paper was supported by Konkuk University in 2017.

\section{Availability of data and materials}

The datasets used in this study are not publicly available due to the limitation of access to the raw data of National Health Insurance Service in Korea. If you need to discuss the dataset, you can e-mail the corresponding author.

\section{Ethics approval and consent to participate}

This study was reviewed and approved by the Institutional Review Boards of Konkuk University(7001355-201909-E-100). This study used the secondary data of NHIS with omitting individual's information, so there was no need of the informed consents from the study population.

\section{Consent for publication}

Not applicable.

\section{Competing interests}

The authors declare that they have no competing interests.

\section{Author details}

'Department of Preventive Medicine, School of Medicine, Konkuk University, Neungdongro 120, Gwangjin-gu, Seoul 05029, Korea. ${ }^{2}$ Health IT Center, College of Medicine, Yonsei University, Seoul, Korea. ${ }^{3}$ Department of Nursing, College of Nursing, Konyang University, Daejeon, Korea.

Received: 30 August 2019 Accepted: 12 February 2020

Published online: 19 February 2020

\section{References}

1. Bray F, Ferlay J, Soerjomataram I, Siegel RL, Torre LA, Jemal A. Global cancer statistics 2018: GLOBOCAN estimates of incidence and mortality worldwide for 36 cancers in 185 countries. CA Ccancer J Clin. 2018;68:394-424

2. Jung KW, Won YJ, Kong HJ, Lee ES. Cancer statistics in Korea: incidence, mortality, survival, and prevalence in 2016. Cancer Res Treat. 2019;51:417-30.

3. Chan AT, Giovannucci EL. Primary prevention of colorectal cancer. Gastroenterology. 2010;138:2029-43.

4. Eckel RH, Grundy SM, Zimmet PZ. The metabolic syndrome. Lancet. 2005; 365:1415-28.

5. Mottillo S, Filion KB, Genest J, Joseph L, Pilote L, Poirier P, et al. The metabolic syndrome and cardiovascular risk: a systematic review and metaanalysis. J Am Coll Cardiol. 2010;56:1113-32.

6. Saklayen MG. The global epidemic of the metabolic syndrome. Current HypertensiReports. 2018;20:1-12.

7. Cameron AJ, Shaw JE, Zimmet PZ. The metabolic syndrome: prevalence in worldwide populations. Endocrinol Metab Clin. 2004;33:351-75.

8. Loucks EB, Rehkopf DH, Thurston RC, Kawachi I. Socioeconomic disparities in metabolic syndrome differ by gender: evidence from NHANES III. Annals of epidemiology. 2007;17:19-26.

9. Kim HR, Han MA. Association between Serum Liver Enzymes and Metabolic Syndrome in Korean Adults. Int J Environ Res Public Health. 2018:15:1658-64.

10. Pelucchi C, Negri E, Talamini R, Levi F, Giacosa A, Crispo A, et al. Metabolic syndrome is associated with colorectal cancer in men. Eur J Cancer. 2010;46: 1866-72.

11. Kabat GC, Kim MY, Peters U, Stefanick M, Hou L, Wactawski-Wende J, et al. A longitudinal study of the metabolic syndrome and risk of colorectal cancer in postmenopausal women. Eur J Cancer Prev. 2012;21:326-32.

12. Aleksandrova $\mathrm{K}$, Boeing $\mathrm{H}$, Jenab $M$, Bueno-de-Mesquita $H B$, Jansen $E$, van Duijnhoven FJ, et. al. Metabolic syndrome and risks of colon and rectal cancer: the European prospective investigation into cancer and nutrition study. Cancer Prev Res. 2011;4:1873-1883.

13. Siddiqui AA, Palmer BF. Metabolic syndrome and its association with colorectal cancer: a review. Am J Med Sci. 2011;341:227-31.
14. Chang LC, Wu MS, Tu CH, Lee YC, Shun CT, Chiu HM. Metabolic syndrome and smoking may justify earlier colorectal cancer screening in men. Gastrointestinal endoscopy. 2014;79:961-9.

15. Morita T, Tabata S, Mineshita M, Mizoue T, Moore MA, Kono S. The metabolic syndrome is associated with increased risk of colorectal adenoma development: the Self-Defense Forces health study. Asian Pac J Cancer Prev. 2005;6:485.

16. World Health Organization. The Asia-Pacific perspective: Redefining obesity and its treatment. Geneva, Switzerland: World Health Organization; 2000.

17. National Health Insurance Service (NHIS). 2017 National health Screening Statistical Yearbook. National Health Insurance Service. 2018.

18. Jinjuvadia R, Lohia P, Jinjuvadia C, Montoya S, Liangpunsakul S. The association between metabolic syndrome and colorectal neoplasm: systemic review and meta-analysis. J Clin Gastroenterol. 2013;47:33.

19. Ahmed RL, Schmitz KH, Anderson KE, Rosamond WD, Folsom AR. The metabolic syndrome and risk of incident colorectal cancer. Cancer. 2006; 107:28-36.

20. Stocks T, Lukanova A, Bjørge T, Ulmer H, Manjer J, Almquist M, et al. Metabolic factors and the risk of colorectal cancer in 580,000 men and women in the metabolic syndrome and cancer project (Me-Can). Cancer. 2011:117:2398-407.

21. Stocks T, Lukanova A, Johansson M, Rinaldi S, Palmqvist R, Hallmans G, et al. Components of the metabolic syndrome and colorectal cancer risk; a prospective study. Int J Obes. 2008;32:304.

22. Kim JH, Lim YJ, Kim YH, Sung IK, Shim SG, Oh SO, et al. Is metabolic syndrome a risk factor for colorectal adenoma? Cancer Epidemiol Prev Biomarkers. 2007;16:1543-6.

23. Godsland IF. Insulin resistance and hyperinsulinaemia in the development and progression of cancer. Clin Sci. 2010;118:315-32.

24. Komninou D, Ayonote A, Richie JP Jr, Rigas B. Insulin resistance and its contribution to colon carcinogenesis. Exp Biol Med. 2003;228:396-405.

25. Riondino S, Roselli M, Palmirotta R, Della-Morte D, Ferroni P, Guadagni F. Obesity and colorectal cancer: role of adipokines in tumor initiation and progression. World J Gastroenterol. 2014;20:5177.

26. Ley RE, Turnbaugh PJ, Klein S, Gordon Jl. Microbial ecology: human gut microbes associated with obesity. Nature. 2006:444:1022.

27. Shen XJ, Rawls JF, Randall TA, Burcall L, Mpande C, Jenkins N, et al. Molecular characterization of mucosal adherent bacteria and associations with colorectal adenomas. Gut Microbes. 2010;1:138-47.

28. Saetang J, Sangkhathat S. Diets link metabolic syndrome and colorectal cancer development. Oncol Rep. 2017;37:1312-20.

29. Pais R, Silaghi H, Silaghi AC, Rusu ML, Dumitrascu DL. Metabolic syndrome and risk of subsequent colorectal cancer. World $J$ Gastroenterol. 2009;15:5141

30. Trabulo D, Ribeiro S, Martins C, Teixeira C, Cardoso C, Mangualde J, et al. Metabolic syndrome and colorectal neoplasms: An ominous association. World J Gastroenterol. 2015;21:5320.

31. Colangelo LA, Gapstur SM, Gann PH, Dyer AR, Liu K. Colorectal cancer mortality and factors related to the insulin resistance syndrome. Cancer Epidemiol Biomarkers Prev. 2002;11:385-91.

32. Esposito K, Chiodini P, Colao A, Lenzi A, Giugliano D. Metabolic syndrome and risk of cancer: a systematic review and meta-analysis. Diabetes care. 2012;35:2402-11.

33. Esposito K, Chiodini P, Capuano A, Bellastella G, Maiorino MI, Rafaniello C, et al. Colorectal cancer association with metabolic syndrome and its components: a systematic review with meta-analysis. Endocrine. 2013;44: $634-47$.

34. Hannan LM, Jacobs EJ, Thun MJ. The association between cigarette smoking and risk of colorectal cancer in a large prospective cohort from the United States. Cancer Epidemiol Biomark Prev. 2009;18:3362-7.

35. Shen Z, Ye Y, Bin L, Yin M, Yang $X$, Jiang $K$, et al. Metabolic syndrome is an important factor for the evolution of prognosis of colorectal cancer: survival, recurrence, and liver metastasis. Am J Surg. 2010;200:59-63.

36. Feltner FJ, Ely GE, Whitler ET, Gross D, Dignan M. Effectiveness of community health workers in providing outreach and education for colorectal cancer screening in Appalachian Kentucky. Soc Work Health Care. 2012;51:430-40.

37. Briant KJ, Sanchez JI, Ibarra G, Escareño M, Gonzalez NE, Jimenez Gonzalez V, Marchello N, Louie S, Thompson B. Using a culturally tailored intervention to increase colorectal Cancer knowledge and screening among Hispanics in a rural community. Cancer Epidemiol Biomark Prev. 2018;27(11):1283-8. 
38. Briant KJ, Wang L, Holte S, Ramos A, Marchello N, Thompson B.

Understanding the impact of colorectal cancer education: a randomized trial of health fairs. BMC Public Health. 2015;15:1196.

39. Wong MC, Ding H, Wang J, Chan PS, Huang J. Prevalence and risk factors of colorectal cancer in Asia. Intestinal Res. 2019;17:317.

40. Choi YJ, Lee DH, Han KD, Yoon H, Shin CM, Park YS, et al. Adult height in relation to risk of cancer in a cohort of 22,809,722 Korean adults. $\mathrm{Br}$ J Cancer. 2019;120:668.

41. Pyo $\mathrm{JH}$, Hong $\mathrm{SN}$, Min $\mathrm{BH}$, Chang $\mathrm{DK}$, Son $\mathrm{HJ}$, Rhee $\mathrm{PL}$, et al. Is height a risk factor for colorectal adenoma? Korean J Intern Med. 2016;31:653-9.

42. Wei EK, Giovannucci E, Wu K, Rosner B, Fuchs CS, Willett WC, et al, Comparison of risk factors for colon and rectal cancer. International journal of cancer. 2004;108:433-42.

43. Yamaguchi N, Mahbub M, Takahashi H, Hase R, Ishimaru Y, Sunagawa H, et al. Plasma free amino acid profiles evaluate risk of metabolic syndrome, diabetes, dyslipidemia, and hypertension in a large Asian population. Environ Health Prev Med. 2017;22:35.

44. Reis J, Spencer PS. Decision-making under uncertainty in environmental health policy: new approaches. Environ Health Prev Med. 2019;24:57.

45. Kim S, Song JH, Oh YM, Park SM. Disparities in the utilisation of preventive health services by the employment status: An analysis of 2007-2012 South Korean national survey. PloS one. 2018;13(12):e0207737.

\section{Publisher's Note}

Springer Nature remains neutral with regard to jurisdictional claims in published maps and institutional affiliations.

Ready to submit your research? Choose BMC and benefit from:

- fast, convenient online submission

- thorough peer review by experienced researchers in your field

- rapid publication on acceptance

- support for research data, including large and complex data types

- gold Open Access which fosters wider collaboration and increased citations

- maximum visibility for your research: over $100 \mathrm{M}$ website views per year

At BMC, research is always in progress.

Learn more biomedcentral.com/submissions 